presumptive diagnosis was made of bleeding from colonic diverticular disease and in view of his age he was treated conservatively. Over the next $\mathbf{4 8}$ hours he had two further episodes of rectal bleeding suggesting melaena associated with an episode of haematemesis, hypotension and tachycardia with a fall in haemoglobin requiring six unit blood. An emergency gastroscopy revealed blood in the duodenum but no other lesion was seen. At operation a large chronic post-bulbar duodenal ulcer was discovered which was eroding into the neck of the gall bladder and the anterior branch of the cystic artery. A partial (Billroth II) gastrectomy was performed and the patient made a full recovery.

Various emergency treatment modalities to arrest cystic artery haemorrhage include endoscopic electrocoagulation or laser therapy, embolisation ${ }^{4}$ of the cystic or right hepatic artery and surgery. The former two options are feared with higher risk of infarction of the gall bladder. At surgery, cystic artery ligation with cholecystectomy has been recommended because ligating the artery and leaving the gall bladder in situ could lead to infarction. ${ }^{1}$ This was certainly not the case in our elderly patient where we simply tied the cystic artery, probably the anterior branch and performed a Billroth II gastrectomy. MUHAMMED ASHRAF MEMON KHALID HUSSAN JM SHENNAN

Department of Surgery, Wirral Hospital NHS Trust, Arrowe Park Hospital, Upton, Wirral, Merseyside L49 SPE, UK

Correspondence to MA Memon, 10 Ridgemere Road, Pensby, Wirral, Merseyside L61 8RL, UK

1 Ford GA, Simpson AH, Gear MW, Wilkinson SP. Duodenal ulceration into the cystic artery Postgrad Med F 1990; 66: 144-6.

2 Glazer HB, Stanley RJ, Koshler RE. Cystic artery haemorrhage. A complication of penetrating duodenal ulcer. Radiology 1980; 136 623-5.

3 Ring SM, Beranbaum ER, Madayag MA, et al. Peptic erosion of the cystic artery. An unusual etiology of spontaneous gastrointestinal hemorrhage. Angiology 1972; 23: 554-7.

4 Cooper SG, Morse SS, Strauss EB. Peptic erosion of the cystic artery with massive duodenal hemorrhage: therapeutic embolizaduodenal hemorrhage: therapeutic embolization. Card

\section{Iatrogenic gall bladder perforation}

Sir

Gall bladder perforation is an uncommon complication of percutaneous kidney biopsy. Several cases have been reported previously, though over 25 years $\operatorname{ago}^{1-3}$ and we describe another, in a 70-year-old man with suspected polyarteritis nodosa.

Biopsy of the right kidney was carried out with the patient in the prone position and a pillow under the abdomen. The longitudinal axis of the right kidney was outlined by mean of ultrasound scanning by a ultrasonographer using a $3.5 \mathrm{MHz}$ curvilinear phased crystal array probe. On scanning, the right kidney was situated in a norma anatomical position. The depth of the lower pole of the kidney was determined using a lumbar puncture needle as well as by ultrasound. One vertical pass to the lower pole of the right kidney, by an experienced operator (MJF), was made with a 1.6 gauge menghini needle and a good sample obtained.
Immediate right-sided flank pain occurred. Post-biopsy blood pressure was stable at $180 / 90 \mathrm{mmHg}$ and he subsequently passed $300 \mathrm{ml}$ of clear urine. His severe flank pain persisted. Abdominal examination revealed right flank tenderness with guarding and normal bowel sounds. Ultrasound scan showed a $2-5 \mathrm{~cm}$ haematoma over the lower pole of the right kidney and free fluid ('probable blood') over the right lobe of the liver.

The patient settled with analgesia, remaining haemodynamically stable and passed a further $250 \mathrm{ml}$ of rosé-coloured urine. Fifteen hours post biopsy his blood pressure dropped acutely to $100 / 60 \mathrm{mmHg}$ and he developed generalised abdominal discomfort. His temperature was $37.5^{\circ} \mathrm{C}$ and he was sweaty with clinically evident generalised peritonitis.

Laboratory investigations revealed: haemoglobin $16 \mathrm{~g} / \mathrm{dl}$, white cell count $12 \times 10^{9} / 1$, platelets $185 \times 10^{9} / 1$ plasma urea $17 \mathrm{mmol} / \mathrm{l}$, sodium $143 \mathrm{mmol} / \mathrm{l}$, potassium $5.1 \mathrm{mmol} / \mathrm{l}$, bicarbonate $20 \mathrm{mmol} / \mathrm{l}$, chloride $109 \mathrm{mmol} / \mathrm{l}$, creatinine $320 \mu \mathrm{mol} / 1$, and amylase 320 Somogoyi Units (normal <250).

There was no free gas on abdominal or chest $\mathrm{X}$-ray.

After rapid resuscitation he underwent emergency laparotomy where bile-stained peritonitis with collections under both diaphragms and in the pelvis was found. There was a pinpoint perforation in the fundus of a small gall bladder which was lying in a normal anatomical position and displayed no evidence of acute inflammation. The omentum had migrated towards the gall bladder but had not sealed the hole. He underwent oversewing of the gall bladder, peritoneal lavage and peritoneal drainage.

He spent 21 days in hospital, his stay being complicated by a lower respiratory tract infection. His impaired renal function remained stable. Report of the biopsy confirmed kidney tissue, but there was no gall bladder tissue present.

Haemorrhagic complications of percutaneous renal biopsy are common (see box), but these are not usually life threatening and serious complications are rare. ${ }^{1-5}$

Usually patients with iatrogenic perforated gall bladders develop pain and hypotension

\section{Complications of percutaneous renal biopsy}

\section{Minor}

Haemorrhagic:

- microscopic and macroscopic haematuria $(50 \%)$

- intra- or peri-renal haemorrhage

- peri-renal haematoma $(1.4 \%$ clinically, $>50 \%$ on CT scanning)

- retro-peritoneal haematoma $(5-10 \%)$

Pain: abdominal or flank (5-10\%)

Infection: renal $(0.18 \%)$

Arteriovenous fistula: renal $(0.1 \%)$

Major

Perforation: pleura, bowel, mesenteric artery, gall bladder

Laceration: liver, spleen, adrenal, pancreas

shortly after the incident. If there is no underlying obstruction of the biliary tree the abdominal pain and hypotension are usually self-limiting, not resulting in peritonitis. ${ }^{6}$

Our case of gall bladder perforation was complicated by peritonitis. We therefore suggest that if a patient develops abdominal pain post renal biopsy he/she should be observed closely and an ultrasound scan performed. Conservative management for a short time is appropriate but early signs of peritoneal irritation demand surgical intervention, acknowledging the possibility of a perforated viscus as a potentially serious complication of a relatively safe procedure. The use of realtime ultrasound during biopsy may help reduce the number of complications.

S BHANDAR

MJ FARR

Department of Renal Medicine, Hull Royal Infirmary, Hull HU3 2fZ, UK

Correspondence to Dr MJ Farr

1 Slotkin EA, Madsen PO. Complications of renal biopsy, incidence of 5000 reported cases. $\mathcal{F}$ Urol 1962; 87: 13-5.

2 Mollard P. Gallbladder perforation during kidney puncture. Paediatrics 1967; 22: 724.

3 Brun C, Raaschone F. Kidney biopsies. Am Med 1958; 24: 676-91.

4 Parish AE. Complications of percutaneous rena biopsy: a report of 37 years experience. Clin biopsy: a report of 37 years

5 Galloway Galloway. DC, Tytle T. Laceration of pesenteric arterys kidney biopsy. South Med $f 1980$ 73: 1413-4.

6 Way L, Sleisenger M. Acute cholycystitis. In

Way L, Sleisenger M. Acute cholycystitis. In
Sleisenger M, Fordtran J. Gastro-intestinal disease. Pathophysiology, diagnosis, management. Philadelphia: WB Saunders Co, 1983, pp 1374-83. 